\title{
DESAIN MODEL PEMBANGUNAN KESATUAN PENGELOLAAN HUTAN (KPH) DI KABUPATEN MAMUJU PROVINSI SULAWESI BARAT
}

\author{
Design Model of Forest Unit Management in Mamuju Regency, West Sulawesi
}

Supratman

\begin{abstract}
The research aimed to designing model of forest unit management based on field situation. The research was conducted in Karossa and Topoyo District, Mamuju Regency, West Sulawesi Province. Collecting data was conducted with documentation study, Focus Group Discussion (FGD), interview and survey methods. Analysis was done that is Qualitative - Descriptive Analysis and Quantitative Descriptive Analysis. Research outcome was obtained the model of forest unit management development linkage with the dynamics of community, IUPHHK, IPKTM, forest industry, resettlement project, and rural region development. To improving the forest unit management development, it needed convergence activity of institution that linkage with forest management.
\end{abstract}

Key words: Model, Management, Forest, Forest Unit Management

\section{PENDAHULUAN}

Luas kawasan hutan Provinsi Sulawesi Barat berdasarkan Peta Paduserasi adalah 1.189.120 ha atau sekitar $70 \%$ dari luas wilayah daratan. Kawasan hutan tersebut terdiri atas hutan lindung $(\mathrm{HL})$ seluas 726.870 ha, hutan produksi terbatas (HPT) seluas 321.607 ha, hutan produksi (HP) seluas 61.300 ha, hutan suaka alam margasatwa (HSAW) seluas 900 ha, dan hutan konversi seluas 78.443 ha.

Kawasan hutan produksi dan hutan produksi terbatas Provinsi Sulawesi Barat, telah dikelola oleh 9 (sembilan) pemegang IUPHHK-HA $(\mathrm{HPH})$, hanya 3 (tiga) di antaranya yang aktif saat ini yaitu, PT. Zedsko Permai dengan luas areal konsesi 30.562 ha, PT. Inhutani I seluas 29.937 ha, dan PT. Rante Mario dengan areal konsesi seluas 114.000 ha. Areal IUPHHK-HA yang tidak aktif, secara de facto bersifat open acces dan menjadi pemicu maraknya illegal logging, perambahan, dan konflik kawasan hutan, yang bermuara pada terjadinya degradasi hutan. Berdasarkan UU No. 41/1999 tentang Kehutanan, pemerintah dan pemerintah daerah yang harus mengambil peran dalam mengatasi permasalahan pengelolaan hutan.

Membangun unit pengelolaan dalam bentuk Kesatuan Pengelolaan Hutan (KPH) pada tingkat tapak merupakan salah satu hal mendasar untuk mewujudkan pelaksanaan tanggung jawab pemerintah dan pemerintah daerah mengelola sumberdaya hutan. Unit pengelolaan (KPH) tersebut perlu didesain sedemikian rupa sesuai situasi lapangan sehingga pembangunan $\mathrm{KPH}$ dapat menjadi kondisi pemungkin (enabling conditions) dicapainya pengelolaan hutan secara berkelanjutan.

Penelitian bertujuan untuk mendesain model pembangunan Kesatuan Pengelolaan Hutan (KPH) berdasarkan situasi lapangan. Hasil penelitian diharapkan menjadi bahan pertimbangan bagi pemerintah dan pemerintah daerah dalam membangun KPH pada tingkat tapak.

\section{BAHAN DAN METODE}

\section{Waktu dan Lokasi}

Penelitian dilaksanakan selama enam bulan, yaitu pada bulan Agustus sampai Desember 2007. Lokasi penelitian adalah desa-desa yang berbatasan langsung dengan areal IUPHHK-HA (HPH) di Kabupaten Mamuju sebagai berikut:

1. Kampung Salu Bijau, Dusun Salu Bijau, Desa Tasokko, Kecamatan Karossa

2. Kampung Salu Lebbo, Dusun Salu Lebbo, Desa Tabolang, Kecamatan Topoyo

3. Kampung Batu Dinding, Dusun Salu Lebbo, Desa Tabolang, Kecamatan Topoyo. 


\section{Teknik Pengumpulan Data}

Data yang dikumpulkan terdiri atas data primer dan data sekunder. Pengumpulan data primer dilakukan melalui teknik wawancara, diskusi terbatas dengan stakeholder, Focus Group Discussion (FGD), serta pengamatan lapangan. Pengumpulan data sekunder dilakukan melalui studi dokumentasi.

\section{Analisis Data}

Data dianalisis secara Qualitative Descriptive Analysis dan Quantitative Descriptive Analysis. Untuk merumuskan model $\mathrm{KPH}$ dilakukan penyederhanaan-penyederhanaan realitas lapangan yang kompleks dengan menggunakan pendekatan model.

\section{HASIL DAN PEMBAHASAN}

\section{Deskripsi Umum Lokasi Penelitian}

\section{Letak Wilayah}

Secara geografis, lokasi penelitian berada pada posisi geografis 1054' - 2023 LS dan 119012' - 119047' BT. Menurut administrasi kehutanan, termasuk wilayah pengurusan Dinas Kehutanan dan Perkebunan Kabupaten Mamuju, Dinas Kehutanan dan Perkebunan Provinsi Sulawesi Barat. Sedangkan berdasarkan wilayah daerah aliran sungai, termasuk dalam wilayah DAS Budong-Budong.

\section{Kawasan Hutan dan Pengelolaannya}

Luas kawasan hutan di lokasi penelitian adalah 154.630 ha, terdiri atas hutan lindung seluas 11.792 ha, hutan produksi seluas 49.894 ha, dan hutan produksi terbatas seluas 92.989 ha, seperti disajikan pada Tabel 1.
Data pada Tabel 1 menunjukkan kawasan hutan yang didominasi oleh kawasan hutan produksi (HP, HPT) yaitu seluas 142.883 ha $(92,4 \%)$, sisanya adalah kawasan hutan lindung seluas 11.792 ha $(7,6 \%)$. Kawasan hutan tersebut mencakup sebesar $77,0 \%$ dari total kawasan hutan produksi dan sebesar $36,5 \%$ dari total kawasan hutan produksi terbatas Kabupaten Mamuju.

Kawasan hutan di lokasi penelitian sebagian besar telah dikelola oleh pemegang HPH/IUPHHK dan HTI (81,0\%). Pada tahun 2007, hanya satu IUPHHK yang aktif melaksanakan kegiatan pemanfaatan hasil hutan kayu yaitu, IUPHHK PT Zedsko Permai, sedangkan empat IUPHHK lainnya tidak aktif masing-masing, IUPHHK PT Aneka Varia (sementara dalam proses pengurusan izin), IUPHHK PT Rante Mario (sementara dalam proses perpanjangan izin) IUPHHK PT. Hayam Wuruk (sementara dalam proses untuk dicabut izinnya). Kondisi ini menyebabkan areal IUPHHK PT Rante Mario dan areal IUPHHK PT. Hayam Wuruk dalam kondisi open access sehingga rawan perambahan.

Berdasarkan hasil pengamatan lapangan, masyarakat telah merambah areal IUPHHK PT Rante Mario dan areal IUPHHK PT. Hayam Wuruk dan mengkonversinya menjadi areal kebun kelapa sawit dan atau kebun kakao. Jumlah masyarakat perambah pada saat ini adalah $1.150 \mathrm{KK}$ yang tersebar pada 46 kelompok lahan. Luas total areal yang dirambah adalah 3.450 ha atau rata-rata seluas $3,0 \mathrm{ha} / \mathrm{KK}$.

Masyarakat perambah mempunyai kemampuan mengelola areal yang telah dirambah tersebut maksimal 2 ha/KK, sehingga ada lahan rata-rata seluas $1,0 \mathrm{ha} / \mathrm{KK}$ yang saat ini dikuasai oleh keluarga petani tetapi tidak dapat dikelola dengan baik, bahkan cenderung ditelantarkan karena faktor topografi yang curam (> 40\%).

Table 1. Forest Area in Research Location

\begin{tabular}{lrrrr}
\hline \multirow{2}{*}{ Area Status } & \multicolumn{2}{c}{ Forest area based on Functions (ha) } & Total (ha) \\
\cline { 2 - 4 } & Forest Protection & $\begin{array}{c}\text { Forest } \\
\text { Production }\end{array}$ & $\begin{array}{c}\text { Forest Limited } \\
\text { Production }\end{array}$ & \\
\hline IUPHHK PT Aneka Varia & - & 5.496 & 5.924 & 11.421 \\
IUPHHK PT Hayam Wuruk & 420 & 8.719 & 20.396 & 29.535 \\
IUPHHK PT Rante Mario & - & 24.843 & 48.171 & 73.014 \\
IUPHHK PT Zedsko Permai & - & - & 3.174 & 3.174 \\
IUPHHK HTI PT. Intani Hutan Lestari & - & 6.105 & 1.966 & 8.071 \\
Open Access & 11.372 & 4.686 & 13.357 & 29.414 \\
\hline Total (ha) & 11.792 & 49.894 & 92.989 & 154.630 \\
\hline
\end{tabular}

Sumber: Kabupaten Mamuju Dalam Angka, 2007 
Hasil FGD dengan kelompok masyarakat perambah diketahui bahwa mereka bersedia bekerjasama dengan Dinas Kehutanan dan pihakpihak terkait lainnya untuk mengelola lahan yang diterlantarkan tersebut dan lahan-lahan kritis lainnya untuk pengembangan Hutan Tanaman Rakyat (HTR) dan atau pengembangan Hutan Kemasyarakat $(\mathrm{HKm})$.

\section{Kependudukan}

Desa-desa di lokasi penelitian dicirikan oleh migrasi masuk penduduk yang tinggi dari Sulawesi Selatan, khususnya dari Kabupaten Bone, Soppeng, Polman, Mamasa dan Kabupaten Tator.

Tujuan migrasi adalah untuk memperoleh lahan usaha tani kebun kakao. Pada umumnya penduduk yang melakukan migrasi, selain mereka yang tidak memiliki lahan usahatani di desa asalnya, juga biasanya mereka yang mempunyai unit usaha yang dapat dikembangkan di desa tujuan seperti berdagang faktor-faktor produksi usahatani atau berdagang hasil usahatani.

Migrasi masuk intensif terjadi pada awal reformasi tahun 1998. Para migran memulai membuka lahan kawasan hutan sepanjang jalan HPH PT Rante Mario di km 1 sampai km 31, difasilitasi oleh tokoh masyarakat setempat. Laju migrasi masuk ke desa-desa di sekitar hutan telah berdampak kepada berkembangnya wilayah pedesaan hutan, dan terjadinya akulturasi pengetahuan budidaya pertanian dan kehutanan dengan masyarakat setempat. Pada sisi yang lain, migrasi masuk mempunyai potensi terjadinya konflik antara migran dengan masyarakat penduduk asli desa-desa di sekitar hutan.

Mata pencaharian penduduk di sekitar hutan pada umumnya adalah petani. Jenis usahatani yang mereka usahakan adalah, kebun kakao, kebun sawit, beternak, dan pedagang.

\section{Desain Model Pembangunan KPH}

\section{Asumsi Model}

Beberapa asumsi membangun model $\mathrm{KPH}$ di lokasi penelitian adalah sebagai berikut:

a. Pengelolaan kawasan hutan berdasarkan UU No. 41 tahun 1999 dan peraturan yang terkait lainnya, sehingga kegiatan yang bertentangan dianggap illegal

b. Hutan dikelola sesuai potensi setiap tapak, prinsip-prinsip kelestarian, dan prinsip aglomerasi usaha dan aglomerasi wilayah c. Seluruh kawasan hutan dipertahankan sebagai kawasan hutan tetap

d. Adanya dukungan masyarakat dan swasta di dalam pengelolaan hutan

e. Adanya dukungan regulasi Pemerintah, Pemerintah Provinsi Sulawesi Barat, dan Pemerintah Kabupaten Mamuju

f. Tersedianya sumberdaya manusia yang kompeten dan dana di dalam kegiatan pengelolaan hutan.

\section{Konsep Model}

Pembangunan model KPH di lokasi penelitian perlu mencermati dinamika masyarakat setempat, dinamika IUPHHK-HA, dan dinamika pembangunan kehutanan.

Kawasan hutan di lokasi penelitian telah mengalami proses dan dinamika pengelolaan yang melibatkan masyarakat, IUPHHK-HA PT. Rante Mario, IUPHHK-HA dan IUPHHK-HT PT. Hayam Wuruk, IUPHHK-HA PT. Zedsko Permai, IPKTM PT Sulbar Perkasa, industri penggergajian kayu, transmigrasi, dan unit-unit usaha masyarakat yang melakukan kegiatan pemanfaatan kawasan hutan, serta pemanfaatan dan atau pemungutan hasil hutan kayu dan bukan kayu. Aktivitas-aktivitas berupa perambahan, konversi kawasan hutan menjadi areal perkebunan kakao dan lahan usahatani lainnya, berkembangnya pemukiman di dalam kawasan hutan, klaim kawasan hutan oleh masyarakat adat, merupakan issu-issu kunci dan merupakan indikasi perlunya membangun sistem pengelolaan yang mengintegrasikan seluruh kepentingan yang ada secara menguntungkan.

Aksesibilitas wilayah yang terus berkembang akibat pembukaan wilayah hutan oleh IUPHHK-HA, menyebabkan tingginya laju migrasi penduduk masuk di lokasi penelitian. Hal ini meningkatkan interaksi sosial-ekonomi masyarakat dan konflik sosial masyarakat terhadap kawasan hutan, yang bermuara pada terjadinya degradasi hutan. Pada sisi yang lain, kawasan hutan di lokasi penelitian harus pula dikelola sesuai prinsip-prinsip pengelolaan hutan lestari. Hal ini merupakan fenomena-fenomena aktual yang harus dipertimbangkan dalam merumuskan konsep model KPH.

Pengelolaan KPH memerlukan dukungan pemerintah, Pemerintah Provinsi Sulawesi Barat, Pemerintah Kabupaten Mamuju, pemegang IUPHHK-HA, lembaga pendukung (seperti LSM, Perguruan Tinggi, lembaga keuangan), dan masyarakat setempat. Oleh karena itu, diperlukan 
kelembagaan pengelola KPH yang kuat (termasuk dukungan SDM) untuk dapat memfasilitasi para pihak mengelola KPH.

Sebagai suatu unit pengelolaan hutan lestari, maka KPH perlu ditata menjadi unit-unit usaha sesuai fungsi kawasan hutan dan potensi setiap tapak. Unit-unit usaha KPH harus didukung oleh batas-batas unit usaha yang jelas dan diakui oleh semua pihak, tersedianya sarana prasarana yang memadai, dukungan dana yang cukup dan berkelanjutan, serta tersedianya pasar yang kompetitif terhadap produk unit-unit usaha $\mathrm{KPH}$.

Berdasarkan konsep tersebut di atas, maka model pembangunan $\mathrm{KPH}$ di lokasi penelitian dapat dilukiskan seperti pada Gambar 1.

\section{Tujuan Pengelolaan}

Kawasan hutan di lokasi penelitian akan dikelola untuk tujuan utama memproduksi hasil hutan kayu dan hasil hutan bukan kayu yang kompatibel.

\section{Faktor-Faktor Berpengaruh terhadap Pencapaian Tujuan}

Hasil diskusi stakeholder dan pengamatan lapangan diketahui situasi umum kawasan hutan dan faktor-faktor yang berpengaruh terhadap pencapaian tujuan pengelolaan hutan seperti disajikan pada Tabel 2.

Hasil identifikasi faktor-faktor tersebut di atas akan menjadi acuan untuk melakukan intervensi yang dibutuhkan untuk pembangunan model KPH di lokasi penelitian.

\section{Strategi Pembangunan KPH}

Mengacu kepada tujuan pengelolaan dan faktor-faktor yang berpengaruh terhadap pencapaian tujuan pengelolaan $\mathrm{KPH}$, dirumuskan strategi pembangunan dan kegiatan-kegiatan pengelolaan KPH di lokasi penelitian seperti disajikan pada Tabel 3.

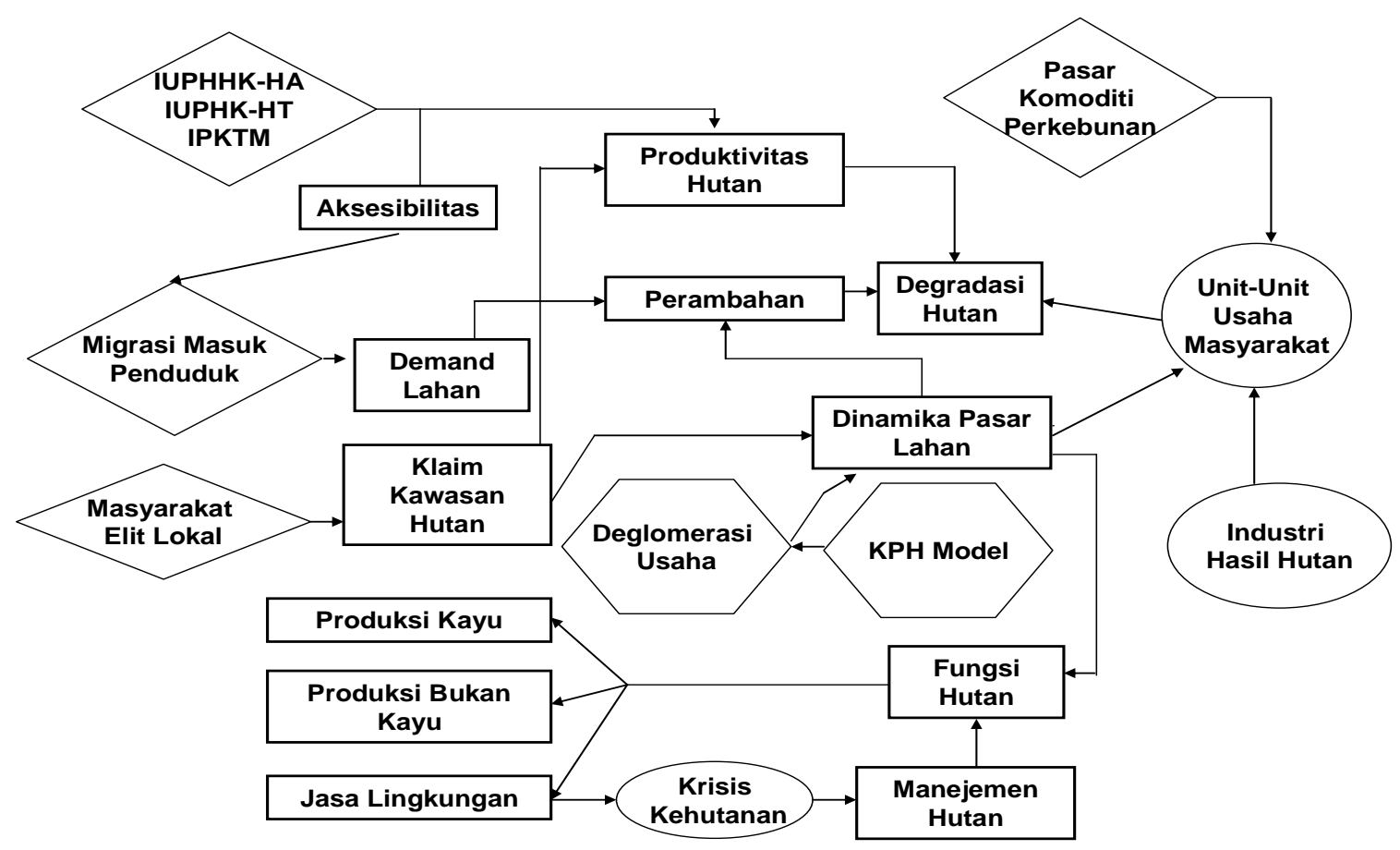

Figure 1. Development Model of Forest Unit Management in Research Location 
Table 2. The Identification Result of Factors that Influence Forest Management Objectives in Research Location

\begin{tabular}{|c|c|c|}
\hline No & Field Situation & Factors \\
\hline 1 & $\begin{array}{l}\text { Konversi kawasan hutan menjadi areal kebun } \\
\text { kakao dan kebun sawit }\end{array}$ & Permintaan lahan usahatani tinggi \\
\hline 2. & $\begin{array}{l}\text { Pemanfaatan/perambahan areal HPH oleh } \\
\text { masyarakat }\end{array}$ & $\begin{array}{l}\text { Pemegang izin HPH tidak melakukan kegiatan } \\
\text { pengelolaan hutan }\end{array}$ \\
\hline 3. & $\begin{array}{l}\text { Migrasi masuk dari Sulawesi Selatan dan Sulawesi } \\
\text { Tengah }\end{array}$ & Aksesibilitas wilayah yang berkembang \\
\hline 4. & $\begin{array}{l}\text { Elit lokal yang membagi-bagi kawasan hutan } \\
\text { kepada pendatang }\end{array}$ & $\begin{array}{l}\text { Kelembagaan formal pengelolaan hutan tidak kuat di } \\
\text { lapangan }\end{array}$ \\
\hline 5. & Konflik horisontal dan vertikal kawasan hutan & Ketiadaan pemangku kawasan hutan \\
\hline 6. & $\begin{array}{l}\text { Masyarakat mempunyai ketergantungan yang } \\
\text { tinggi atas lahan kawasan hutan }\end{array}$ & Permintaan lahan usahatani tinggi \\
\hline 7. & $\begin{array}{l}\text { Ketidak pastian masyarakat berusaha di dalam } \\
\text { kawasan hutan }\end{array}$ & $\begin{array}{l}\text { Masyarakat memanfaatkan kawasan hutan tidak } \\
\text { melalui mekanisme perizinan yang sah }\end{array}$ \\
\hline 8. & Pemanfaatan hasil hutan kayu oleh masyarakat & Permintaan hasil hutan kayu tinggi \\
\hline 9. & Pengusahaan hutan rakyat & Penerbitan izin-izin IPKTM \\
\hline 10. & Berkembang industri penggergajian skala kecil & Permintaan hasil hutan kayu tinggi \\
\hline 11. & Banyak pedagang kayu hasil illegal logging & Profit margin perdagangan kayu illegal yang tinggi \\
\hline 12. & $\begin{array}{l}\text { IUPHHK-HA PT. Rante Mario dan PT. Hayam } \\
\text { Wuruk yang tidak aktif }\end{array}$ & Buruknya kinerja IUPHHK-HA \\
\hline 13. & IUPHHK-HA PT. Zedsko Permai yang aktif & Penerbitan izin IUPHHK-HA \\
\hline 14. & Klaim kawasan hutan oleh masyarakat lokal & $\begin{array}{l}\text { Elit lokal mengakui kawasan hutan sebagai milik } \\
\text { masyarakat adat }\end{array}$ \\
\hline 15. & Terdapat kelompok masyarakat perambah hutan & Migrasi masuk penduduk yang tinggi \\
\hline 16. & $\begin{array}{l}\text { Struktur pengelolaan hutan oleh masyarakat yang } \\
\text { tidak terintegrasi dengan industri }\end{array}$ & $\begin{array}{l}\text { Belum terbangun kemitraan antar masyarakat dengan } \\
\text { IUPHHK dan industri kehutanan }\end{array}$ \\
\hline 17. & Pengawasan tidak efektif & $\begin{array}{l}\text { Belum ada institusi pemerintah yang memberikan } \\
\text { pelayanan publik kehutanan dan pengelolaan hutan } \\
\text { di lapangan }\end{array}$ \\
\hline
\end{tabular}

Table 3. Development Strategy and Management Activity of Forest Unit Management

\begin{tabular}{|c|c|c|}
\hline & Development Strategies & Management Activities \\
\hline 1. & $\begin{array}{l}\text { Meningkatkan pelayanan publik } \\
\text { usaha kehutanan }\end{array}$ & $\begin{array}{l}\text { - Membangun infrastruktur fisik dan infrastruktur sosial yang } \\
\text { mendukung berkembangnya unit-unit usaha kehutanan dan industri } \\
\text { kehutanan } \\
\text { - Memfasilitasi penerbitan izin-izin pemungutan dan pemanfaatan hasil } \\
\text { hutan kepada unit-unit ekonomi (pengusaha, petani, koperasi, dll) }\end{array}$ \\
\hline 2. & $\begin{array}{l}\text { Memperkuat status pengelolaan } \\
\text { kawasan hutan }\end{array}$ & $\begin{array}{l}\text { - Penataan unit-unit usaha sesuai potensi dan fungsi setiap tapak } \\
\text { kawasan hutan } \\
\text { - Membangun sistem pembukaan wilayah hutan yang efisien } \\
\text { - Melaksanakan kegiatan pemanfaatan hasil hutan }\end{array}$ \\
\hline 3. & Rehabilitasi Hutan dan Lahan & $\begin{array}{l}\text { - Pengembangan hutan rakyat } \\
\text { - Pembangunan HTR } \\
\text { - Pengembangan HKm }\end{array}$ \\
\hline 4. & $\begin{array}{l}\text { Penguatan Kelembagaan Usaha } \\
\text { Kehutanan Masyarakat }\end{array}$ & $\begin{array}{l}\text { - Membangun wilayah aglomerasi usaha kehutanan } \\
\text { - Membangun kelembagaan kelompok usaha kehutanan mikro seperti } \\
\text { koperasi, KUB, dll. } \\
\text { - Membangun sistem kelembagaan keuangan mikro seperti BLU } \\
\text { - Mengembangkan struktur sistem kemitraan antara petani, elit lokal, } \\
\text { pedagang, dan industri pengolahan hasil hutan }\end{array}$ \\
\hline
\end{tabular}




\section{Kelembagaan KPH}

\section{Struktur Organisasi KPH}

Sesuai dengan peraturan perundangan, hirarki wilayah pengelolaan hutan terdiri atas wilayah provinsi, kabupaten/kota, dan unit pengelolaan. Wilayah provinsi dan kabupaten/kota merupakan wilayah pengurusan, sedangkan unit pengelolaan merupakan wadah kegiatan pengelolaan hutan. Dengan demikian, wilayah provinsi dan kabupaten/kota adalah merupakan infrastruktur untuk memberikan pelayanan terhadap unit pengelolaan sebagai struktur, sedang pemerintah mempunyai posisi sebagai suprastruktur yang memberikan pelayanan baik kepada infrastruktur maupun struktur dalam pengelolaan hutan.

Sesuai dengan PP 44 tahun 2004 Pasal 32 ayat (2) institusi pengelola bertanggung jawab terhadap penyelenggaraan pengelolaan hutan yang meliputi: (1) perencanaan pengelolaan, (2) pengorganisasian, (3) pelaksanaan pengelolaan, dan (4) pengendalian dan pengawasan. Sebagai konsekuensi dari pemberian tanggung jawab tersebut, maka diperlukan kejelasan hak dan wewenang dari institusi pengelola agar tanggung jawab tersebut dapat dilaksanakan. Format distribusi tanggung jawab, hak dan kewenangan yang jelas di dalam kelembagaan $\mathrm{KPH}$ merupakan prasyarat bagi terwujudnya $\mathrm{KPH}$ di lapangan.

$\mathrm{KPH}$ dilihat dari perspektif kelembagaan merupakan pengaturan/ pembagian kewenangan. Sebagai contoh, dalam proses perencanaan, institusi pengelola mempunyai kewenangan penuh dalam perencanaan yang implementasinya antara lain dalam bentuk pengesahan rencana, sedangkan pemegang IUPHH terbatas pada proses penyusunan rencana. KPH dilihat dari perspektif teknis, melaksanakan kegiatan pengelolaan hutan di lapangan seperti tata hutan, pengaturan hasil, dan lain-lain.

Mengacu kepada Peraturan Kepala Badan Planologi Kehutanan No. SK.80/VII-PW/2006, organisasi KPH adalah lembaga pemerintah atau Badan Usaha Milik Negara yang diberi kewenangan untuk mengelola KPH. Selain sebagai wujud terbentuknya wilayah pengelolaan hutan, $\mathrm{KPH}$ juga sebagai lembaga yang menjalankan pelayanan (pengaturan) dan atau usaha. Fungsi pelayanan (pengaturan) dan atau usaha yang diperankan oleh suatu lembaga KPH sangat bergantung pada masalah yang dihadapi serta sumberdaya yang tersedia.

KPHP dibentuk tidak menggantikan lembaga kehutanan di daerah, melainkan menguatkan fungsi lembaga kehutanan di daerah. Oleh karena itu pembentukan KPH didasarkan pada proses yang dapat mengakomodasikan kekhasan dan aspirasi daerah, penetapan tujuan usaha, karakteristik sumberdaya hutan, batas administrasi wilayah, serta kapasitas dan kapabilitas lembaga yang akan terlibat.

Bentuk keterkaitan antara fungsi-fungsi manajemen pengelolaan hutan yang akan dijalankan oleh $\mathrm{KPH}$, kewenangan pemerintah dan pemerintah daerah serta pengorganisasian kegiatan pembangunan kehutanan dapat dilihat pada Gambar 2.

Berdasarkan uraian pada Gambar 2, serta mengacu kepada PP No. 41/2007 tentang Organisasi Perangkat Daerah, Pasal 14 ayat 6, bentuk kelembagaan KPH di lokasi penelitian adalah Unit Pelaksana Teknis (UPT) Dinas Kehutanan dan Perkebunan. Struktur organisasi $\mathrm{KPH}$ di lokasi penelitian, seperti disajikan pada Gambar 3.

Kelembagaan $\mathrm{KPH}$ adalah fungsional yang mempunyai kompetensi dalam penyelenggaraan pengelolaan hutan. Kelembagaan $\mathrm{KPH}$ melaksanakan sebagian kegiatan teknis operasional dan/atau kegiatan penunjang dengan wilayah kerja satu atau beberapa kecamatan. Kegiatan teknis operasional yang dilaksanakan $\mathrm{KPH}$ adalah tugas untuk melaksanakan kegiatan teknis yang secara langsung berhubungan dengan pelayanan masyarakat sedangkan teknis penunjang adalah melaksanakan kegiatan untuk mendukung pelaksanaan tugas Kepala Dinas Kehutanan dan Perkebunan.

\section{Konvergensi Kegiatan}

Untuk melaksanakan strategi pembangunan dan kegiatan-kegiatan pengelolaan $\mathrm{KPH}$, memerlukan dukungan lembaga-lembaga pemerintah, pemerintah daerah, swasta, dan lembaga pendukung seperti Perguruan Tinggi, LSM, dan lembaga keuangan. Dukungan lembagalembaga tersebut dapat secara individu lembaga atau berkolaborasi dengan lembaga lain yang terkait, melalui konvergensi kegiatan sesuai potensi yang dimiliki masing-masing lembaga, seperti disajikan pada Tabel 4. 


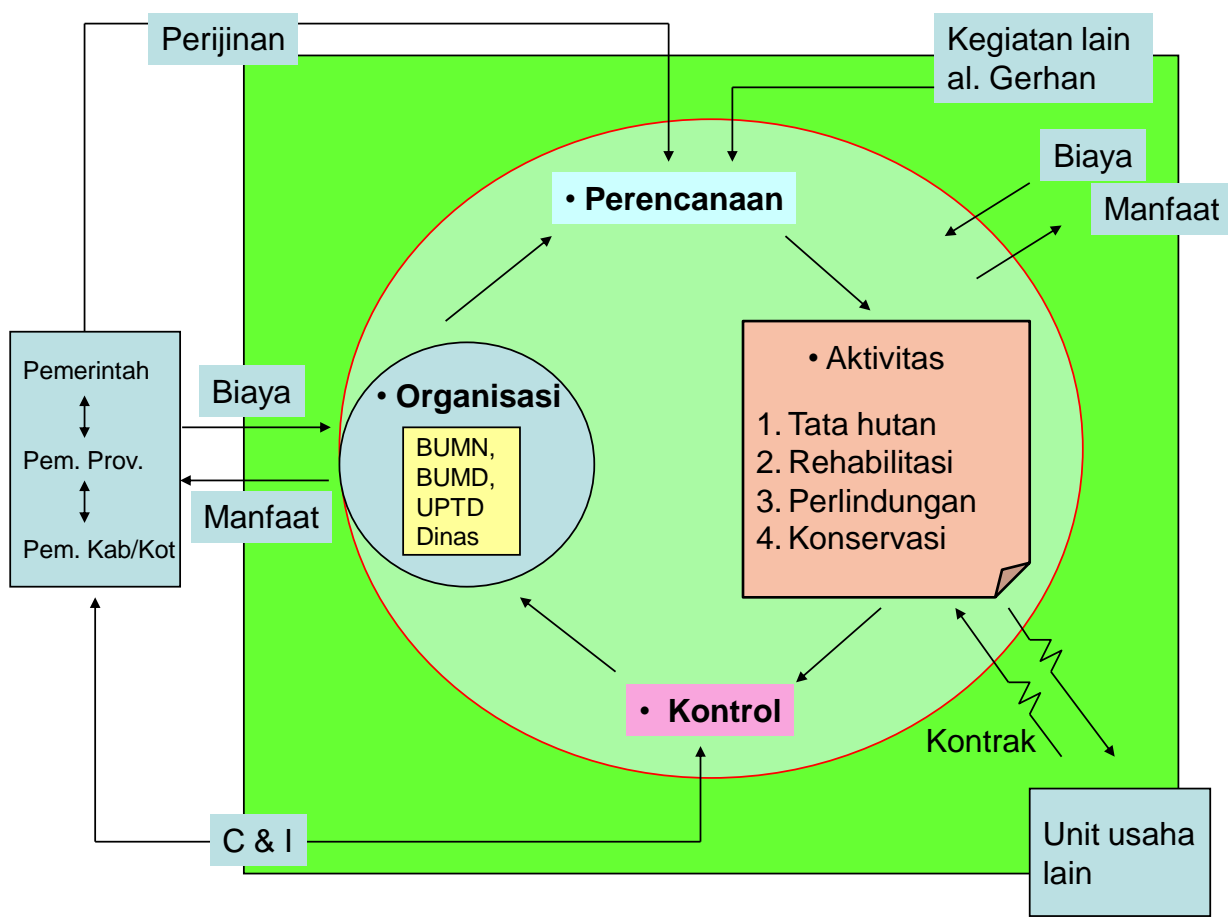

Figure 2. The Position of Forest Unit Management Organization in Forest Administration

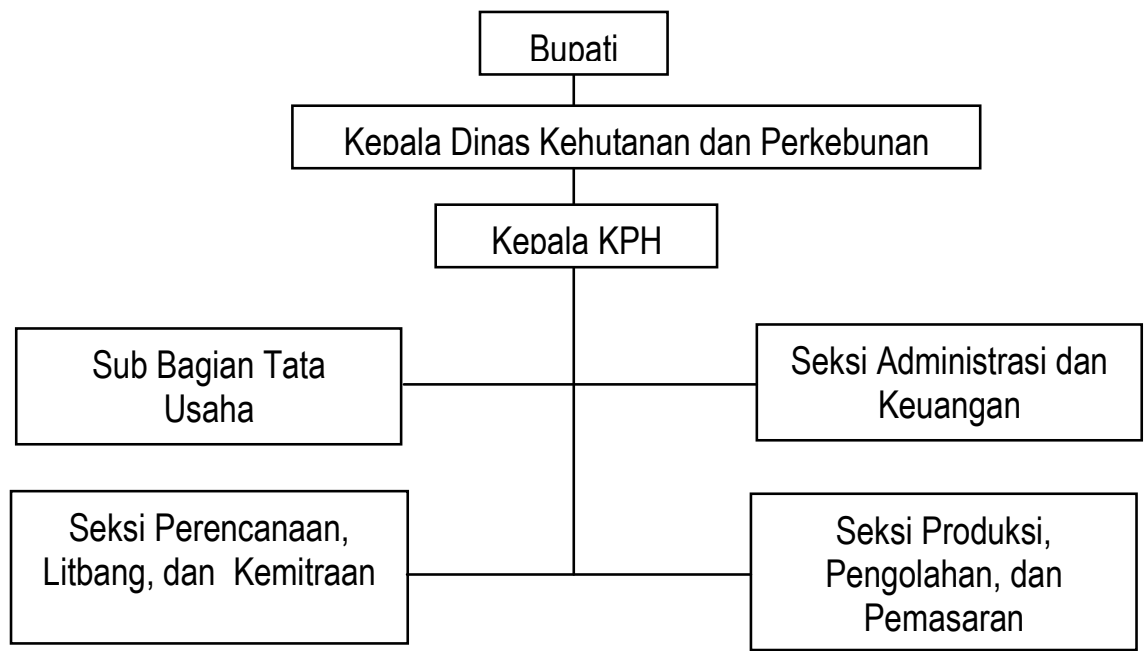

Figure 3. Forest Unit Management Organization 


\section{KESIMPULAN DAN SARAN}

\section{Kesimpulan}

1. Model pembangunan KPH di Kabupaten Mamuju terkait dengan dinamika-dinamika masyarakat, IUPHHK, IPKTM, industri hasil hutan, transmigrasi, dan perkembangan wilayah pedesaan.

2. Tujuan pengelolaan hutan oleh $\mathrm{KPH}$ adalah memproduksi hasil hutan kayu dan hasil hutan bukan kayu yang kompatibel.

3. Strategi pembangunan $\mathrm{KPH}$ adalah meningkatkan pelayanan publik usaha kehutanan, memperkuat status kawasan hutan, rehabilitasi hutan dan lahan, dan penguatan kelembagaan usaha kehutanan masyarakat.

4. Struktur organisasi yang sesuai untuk mengelola KPH adalah Unit Pelaksana Teknis (UPT) Dinas Kehutanan dan Perkebunan Kabupaten Mamuju.

\section{Saran}

Perlu konvergensi kegiatan dari institusi yang terkait untuk mempercepat pembangunan $\mathrm{KPH}$ di Kabupaten Mamuju.

\section{DAFTAR PUSTAKA}

Anonim, 2004. Peraturan Pemerintah Republik Indonesia Nomor 44 Tahun 2004 Tentang Perencanaan Kehutanan. Sekretariat Negara. Jakarta.

Planologi Kehutanan No. SK.80/VII-
PW/2006 tentang Pedoman
Pembangunan Kesatuan Pengelolaan
Hutan (KPH) Model. Jakarta.
----- --, 2007. Peraturan Pemerintah Republik
Indonesia Nomor 41 Tahun 2007 Tentang
Organisasi Perangkat Daerah. Sekretariat
Negara. Jakarta.
----, 2007. Peraturan Pemerintah Republik
Indonesia Nomor 6 Tahun 2007 Tentang
Tata Hutan Dan Penyusunan Rencana
Pengelolaan Hutan, Serta Pemanfaatan
Hutan. Sekretariat Negara. Jakarta.

Badan Pusat Statististik (BPS) Kabupaten Mamuju, 2007. Kabupaten Mamuju Dalam Angka. Mamuju.

Diterima: 23 September 2007

\section{Supratman}

Lab. Kebijakan dan Kewirausahaan Kehutanan

Jurusan Kehutanan, Universitas Hasanuddin

Kampus Tamalanrea, Jl. Perintis Kemerdekaan Km. 10, Makassar 90245

Telp./Fax. 0411-585917. Indonesia 
Table 4. The Convergence Matrix of the Development Activities of Forest Management Unit

\begin{tabular}{|c|c|c|c|c|c|c|c|c|c|c|c|c|}
\hline \multirow[b]{3}{*}{ Institusi } & \multicolumn{12}{|c|}{ Strategi Pembangunan dan Kegiatan Pengelolaan KPH } \\
\hline & \multicolumn{2}{|c|}{$\begin{array}{l}\text { Meningkatkan pelayanan } \\
\text { publik kehutanan di } \\
\text { lapangan }\end{array}$} & \multicolumn{3}{|c|}{$\begin{array}{l}\text { Memperkuat status pengelolaan kawasan } \\
\text { hutan }\end{array}$} & \multicolumn{3}{|c|}{ Rehabilitasi Hutan } & \multicolumn{4}{|c|}{ Penguatan Kelembagaan } \\
\hline & \begin{tabular}{|c|} 
Membangun \\
Infrastruktur \\
Pengelolaan \\
Hutan
\end{tabular} & $\begin{array}{l}\text { Fasilitasi } \\
\text { Penerbitan } \\
\text { Izin-izin }\end{array}$ & $\begin{array}{l}\text { Penataan } \\
\text { Unit-unit } \\
\text { Usaha } \\
\text { Kehutanan }\end{array}$ & $\begin{array}{c}\text { Melaksanaka } \\
\text { n Kegiatan } \\
\text { Pengelolaan }\end{array}$ & $\begin{array}{l}\text { Membangun } \\
\text { Sistem PWH } \\
\text { yang Efisien }\end{array}$ & $\mathrm{HR}$ & HTR & HKM & $\begin{array}{l}\text { Membangun } \\
\text { Wilayah } \\
\text { Aglomerasi } \\
\text { Usaha }\end{array}$ & $\begin{array}{c}\text { Membangun } \\
\text { Kelompok } \\
\text { Usaha } \\
\text { Kehutanan } \\
\text { Mikro }\end{array}$ & $\begin{array}{l}\text { Membangun } \\
\text { Lembaga } \\
\text { Keuangan } \\
\text { Mikro }\end{array}$ & $\begin{array}{l}\text { Sistem } \\
\text { Kemitraan }\end{array}$ \\
\hline Menteri & $\mathrm{X}$ & $\mathrm{X}$ & & & & & $\mathrm{X}$ & $X$ & & & $\mathrm{X}$ & \\
\hline Gubernur & $\mathrm{X}$ & $X$ & & & & & $\mathrm{X}$ & $\mathrm{X}$ & $\mathrm{X}$ & & $\mathrm{X}$ & $\mathrm{X}$ \\
\hline Bupati & $\mathrm{X}$ & $\mathrm{X}$ & $\mathrm{X}$ & & & & $\mathrm{X}$ & $\mathrm{X}$ & $\mathrm{X}$ & & $\mathrm{X}$ & $\mathrm{X}$ \\
\hline Baplan & $\mathrm{X}$ & & $X$ & & & & $\mathrm{X}$ & $\mathrm{X}$ & & & & \\
\hline Dirjen RLPS & $\mathrm{X}$ & & & & & & & $\mathrm{X}$ & & & & \\
\hline $\begin{array}{l}\text { Dirjen Bina } \\
\text { Produksi }\end{array}$ & $X$ & $\mathrm{X}$ & & & & & $X$ & & & & & \\
\hline BP DAS & $X$ & & & & & & & $X$ & & & & \\
\hline \multicolumn{13}{|l|}{ BDK } \\
\hline $\begin{array}{l}\text { Dinas } \\
\text { Kehutanan } \\
\text { Provinsi }\end{array}$ & $X$ & $x$ & $X$ & & $X$ & & $X$ & $X$ & $X$ & & $X$ & $X$ \\
\hline $\begin{array}{l}\text { Dinas } \\
\text { Kehutanan } \\
\text { Kabupaten }\end{array}$ & $X$ & $x$ & $X$ & $x$ & $x$ & $X$ & $X$ & $x$ & $x$ & $x$ & $x$ & $X$ \\
\hline IUPHHK-HA & $X$ & $X$ & $X$ & $X$ & $X$ & & & & $X$ & $X$ & $X$ & $X$ \\
\hline $\begin{array}{l}\text { Industri Hasil } \\
\text { Hutan }\end{array}$ & $x$ & $x$ & & $x$ & $X$ & $X$ & & $x$ & $x$ & $x$ & $x$ & $X$ \\
\hline Masyarakat & $X$ & $X$ & $X$ & $X$ & $X$ & $X$ & $X$ & $X$ & $X$ & $X$ & $X$ & $X$ \\
\hline $\begin{array}{l}\text { Perguruan } \\
\text { Tinggi }\end{array}$ & $x$ & & $x$ & & $X$ & & $X$ & $X$ & $x$ & $x$ & $x$ & $X$ \\
\hline LSM & $X$ & & $\mathrm{X}$ & & & & $\mathrm{X}$ & $X$ & & $\mathrm{X}$ & $X$ & $\mathrm{X}$ \\
\hline
\end{tabular}

Keterangan: $\mathrm{X}$ institusi yang berperan pada setiap kegiatan pembangunan dan pengelolaan $\mathrm{KPH}$ 